\title{
Single nucleotide polymorphisms associated with carcass traits in a population of Brahman and Brahman-influenced steers
}

\author{
A.M. Royer $^{1,2}$, C. Shivers ${ }^{3}$, D.G. Riley ${ }^{4}$, M.A. Elzo ${ }^{5}$ and M.D. Garcia ${ }^{1,2}$ \\ ${ }^{1}$ Department of Animal Science, Louisiana State University, Baton Rouge, \\ LA, USA \\ ${ }^{2}$ Louisiana State University AgCenter, Baton Rouge, LA, USA \\ ${ }^{3}$ American Brahman Breeders Association, Houston, TX, USA \\ ${ }^{4}$ Department of Animal Science, Texas A\&M University, College Station, TX, \\ USA \\ ${ }^{5}$ Department of Animal Sciences, University of Florida, Gainesville, FL, USA \\ Corresponding author: M.D. Garcia \\ E-mail: Mgarcia@agcenter.lsu.edu
}

Genet. Mol. Res. 15 (2): gmr.15028280

Received December 15, 2015

Accepted February 11, 2016

Published June 21, 2016

DOI http://dx.doi.org/10.4238/gmr.15028280

\begin{abstract}
Brahman cattle are important in tropical regions due to their ability to tolerate excessive heat and parasites. However, Brahman cattle exhibit lower carcass quality characteristics when compared to Bos taurus breeds. The objective of this study was to evaluate potential associations between single nucleotide polymorphisms (SNPs) in six candidate genes for carcass quality and composition traits in a population of Brahman and Brahman-influenced steers. Steers were evaluated through the American Brahman Breeders Association carcass evaluation project in Gonzales, Texas. Carcass traits measured included hot carcass weight, ribeye area, marbling score, yield grade, quality grade, dressing percent, and Warner-Bratzler shear force score. Six previously described candidate genes were chosen for SNP analysis based on their previous association with growth and carcass traits.
\end{abstract}


Candidate genes utilized in the current study included calpastatin $(C A S T)$, calpain $(C A P N 3)$, thyroglobulin $(T G)$, growth hormone, insulin growth factor 1, and adiponectin. Six unique SNPs from three candidate genes (TG, CAST, and CAPN3) were significantly associated $(\mathrm{P}<0.001)$ with carcass quality traits (marbling score and quality grade). A genotypic effect was observed for all significant SNPs, with differing levels of performance observed for animals inheriting different genotypes. Although multiple SNPs in the current study were significantly $(\mathrm{P}<0.001)$ associated with growth and carcass traits, they should be validated in larger populations prior to implementation in selection strategies.

Key words: Bos indicus; Carcass traits; Carcass quality

\section{INTRODUCTION}

Multiple tools have been developed to improve the accuracy of animal selection and rate of improvement in economically important traits in beef cattle. The identification and utilization of molecular markers have increased the rate of genetic improvement as compared with other currently utilized selection tools (Davis and DeNise, 1998). The candidate gene approach evaluates single nucleotide polymorphisms (SNPs) located on genes of known physiological function and analyzes their potential associations with economically important traits. This may be especially useful for Bos indicus cattle, which are known to exhibit less desirable growth, performance, and carcass characteristics when compared to Bos taurus cattle (Wheeler et al., 2001).

The current study evaluated SNPs located within six known candidate genes to evaluate potential associations with growth traits, feedlot performance, and carcass traits. The candidate genes included adiponectin $(A D I P O Q)$, thyroglobulin $(T G)$, calpain-III (CAPN3), calpastatin (CAST), insulin like growth factor $(I G F 1)$, and growth hormone (GH1), based on previous reports linking them to growth traits, carcass quality, and composition traits. Specifically, the candidate genes utilized herein have previously been reported to be associated with animal growth curves (Bauman, 1992; Machado et al., 2003; Pereira et al., 2005; Mullen et al., 2010), carcass traits such as marbling (Casas et al., 2005; Van Eenennaam et al., 2007), rib eye area (Morsci et al., 2006), back fat thickness (Shin and Chung 2013), and tenderness (Koohmaraie et al., 2002; Schenkel et al., 2006).

Thus, the objective of the current study was to evaluate SNPs located in these six candidate genes and their potential associations with carcass quality and composition traits in a population of Brahman and Brahman-influenced steers.

\section{MATERIAL AND METHODS}

All animals were treated and maintained in accordance with the principles and guidelines outlined in the Guide for the Care and Use of Agricultural Animals in Research and Teaching (Protocol \#AE2009-21). The studied animal population included a total of 42 Brahman $(\mathrm{N}=31)$ and Brahman-influenced $(\mathrm{N}=11)$ steers born from 2009 to 2014 at the LSU AgCenter Central Research Station in Baton Rouge, LA. After weaning, steers were 
shipped to a commercial feedyard in Gonzales, TX, to complete the finishing process. Steers were processed individually upon arrival to the feedyard and were sorted into appropriate pens based on weight, frame size, and condition. When individual pens reached an average weight and body condition deemed acceptable $(1 \mathrm{~cm}$ backfat and $544 \mathrm{~kg}$ body weight) animals were sent to a commercial packing plant for the collection of carcass quality and composition traits. Carcass traits collected included hot carcass weight (HCW), ribeye area (REA), marbling score (MARB), yield grade (YG), quality grade (QG), dressing percent (DRESS), and WarnerBratzler shear force score (WBS).

A 20-mL blood sampled was collected from each steer via jugular venipuncture. After collection, blood was transferred to two $15-\mathrm{mL}$ tubes and centrifuged at $2800 \mathrm{~g}$ for $20 \mathrm{~min}$ at $4^{\circ} \mathrm{C}$. DNA was then extracted from white cell buffy coats using a Saturated Salt Procedure previously described by Miller et al. (1988). Purified DNA samples were diluted to form 25$\mathrm{ng} / \mu \mathrm{L}$ working solutions in preparation for genotyping.

Previously described SNPs were selected equidistantly across the $T G, A D I P O Q$, $C A S T, C A P N 3, I G F 1$, and $G H 1$ genes for genotyping utilizing dbSNP (http://www.ncbi.nlm. nih.gov/projects/SNP). A total of 149 SNPs were selected from the six candidate genes and equidistant SNPs were selected to account for possible linkage between selected SNPs and potential causative mutations. Genotyping was performed by Neogen LLC (Lincoln, NE, USA) utilizing a Sequenom MassArray genotyping platform (San Diego, CA, USA).

The mixed model procedure in SAS (version 9.4, SAS Institute, Cary, NC, USA) was used to evaluate associations of SNPs in the candidate genes (ADIPOQ, CAPN3, CAST, TG, $I G F 1$, and $G H 1$ ) with carcass quality and composition traits. Models were fitted individually for each trait. Traits were HCW, REA, MARB, YG, QG, DRESS, and WBS. Fixed effects in the model were breed group and SNP genotype as main and interaction effects. Random effects were sire and residual. The LSMEANS procedure and the pre-planned pairwise comparison functions were utilized to evaluate significant differences in performance for a trait when inheriting different genotypes from a significant SNP. Any SNP with only one genotype or any SNP that failed to generate genotypes for less than $50 \%$ of the experimental animals was excluded from the analysis due to a lack of marker effects. A total of 70 SNPs met these criteria, and a Bonferroni correction was applied to account for multiple testing. Thus, significance was set at $\mathrm{P}<0.001$.

\section{RESULTS}

When evaluating SNPassociations with HCW, REA, and YG, no significant associations $(\mathrm{P}<0.001)$ were detected in any of the candidate genes after Bonferroni correction. However, six unique SNPs located in the $T G, C A P N 3$, and $C A S T$ genes were identified as significant ( $\mathrm{P}$ $<0.001$ ) when evaluating MARB and QG (Table 1).

$T G$ was the only gene in the current study to contain an SNP that was significantly associated with MARB. Markers rs11050123, rs135059985, and rs133980693 showed that animals inheriting the respective minor allele genotypes had significantly larger MARB than animals inheriting the respective heterozygous or major allele genotypes (Table 2). No significant differences were observed when comparing the heterozygous and major allele genotypes for these SNPs. The opposite genotypic effect was observed for the marker rs378567477, whereby animals inheriting the major allele genotype had larger MARB than animals inheriting the minor allele and heterozygous genotypes. No significant difference was observed when comparing the minor allele and heterozygous genotypes for this marker. 
Table 1. Level of significance and frequency of animals from each genotype associated with carcass quality traits.

\begin{tabular}{l|c|c|c|c|c|c|c|c}
\hline Traits & Gene & SNP ID & Allele* & $\begin{array}{c}\text { Minor } \\
\text { genotype } \\
\text { frequency } \\
(\mathrm{N})\end{array}$ & $\begin{array}{c}\text { Heterozygous } \\
\text { genotype } \\
\text { frequency } \\
(\mathrm{N})\end{array}$ & $\begin{array}{c}\text { Major } \\
\text { genotype } \\
\text { frequency (N) }\end{array}$ & $\begin{array}{c}\text { SNP } \\
\text { P value }\end{array}$ & $\begin{array}{c}\text { Breed } \\
\mathrm{x} \\
\text { SNP } \\
\text { P value }\end{array}$ \\
\hline MARB & TG & rs110501231 & C/T & 9 & 22 & 10 & $<0.0001$ & 0.0127 \\
\hline MARB & TG & rs133980693 & G/A & 9 & 22 & 10 & $<0.0001$ & 0.0127 \\
\hline MARB & TG & rs135059985 & C/T & 9 & 22 & 10 & $<0.0001$ & 0.0127 \\
\hline MARB & TG & rs378567477 & T/C & 8 & 16 & 9 & 0.0007 & 0.0839 \\
\hline QG & CAPN3 & rs109050259 & G/A & 2 & 23 & 16 & 0.0009 & 0.2217 \\
\hline QG & CAST & rs110496242 & G/A & 2 & 10 & 29 & 0.0003 & 0.0412 \\
\hline
\end{tabular}

MARB, marbling; QG, quality grade; SNP, single nucleotide polymorphism sequence identification. *Minor allele is shown on the left.

Table 2. Single nucleotide polymorphisms associated with carcass quality traits and least square means estimates between genotypes.

\begin{tabular}{l|c|c|c|c|c|c}
\hline Traits & Gene & SNP ID & Allele* & Minor genotype (mean) & Heterozygous genotype (mean) & Major genotype (mean) \\
\hline MARB & TG & rs110501231 & C/T & $547.50 \pm 21.59^{\mathrm{a}}$ & $433.15 \pm 16.07^{\mathrm{b}}$ & $371.11 \pm 32.19^{\mathrm{b}}$ \\
\hline MARB & TG & rs133980693 & G/A & $547.50 \pm 21.60^{\mathrm{a}}$ & $433.15 \pm 16.07^{\mathrm{b}}$ & $371.11 \pm 32.19^{\mathrm{b}}$ \\
\hline MARB & TG & rs135059985 & C/T & $547.50 \pm 21.60^{\mathrm{a}}$ & $433.15 \pm 16.07^{\mathrm{b}}$ & $371.11 \pm 32.19^{\mathrm{b}}$ \\
\hline MARB & TG & rs378567477 & T/C & $372.86 \pm 34.61^{\mathrm{a}}$ & $446.11 \pm 21.58^{\mathrm{a}}$ & $547.50 \pm 22.89^{\mathrm{b}}$ \\
\hline QG & CAPN3 & rs109050259 & G/A & $595.66 \pm 24.70^{\mathrm{a}}$ & $699.39 \pm 9.16^{\mathrm{b}}$ & $704.22 \pm 9.43^{\mathrm{b}}$ \\
\hline QG & CAST & rs110496242 & G/A & $668.14 \pm 24.91^{\mathrm{ab}}$ & $637.81 \pm 13.62^{\mathrm{a}}$ & $706.94 \pm 8.20^{\mathrm{b}}$ \\
\hline
\end{tabular}

MARB, marbling score; QG, quality grade; SNP, single nucleotide polymorphism sequence identification. *Minor allele represented on the left. Different superscript letters indicate a difference within rows at $\mathrm{P}<0.05$.

Two SNPs located in the CAST and CAPN3 genes were identified as being significantly associated $(\mathrm{P}<0.001)$ with $\mathrm{QG}$. Animals that inherited the heterozygous and major allele genotypes for the marker rs109050259, located on the CAPN3 gene, had significantly higher QG scores than animals that inherited the minor allele genotype, although this was not significant. Individuals inheriting the major allele genotype for the marker rs110496242 had significantly higher QG measurements when compared to individuals that inherited the heterozygous genotype. However, no significant difference was observed between individuals that inherited the minor allele genotype and those who inherited the major allele and heterozygous genotypes (Table 2).

\section{DISCUSSION}

Four SNPs located within the $T G$ gene were significantly associated $(\mathrm{P}<0.001)$ with carcass quality and composition traits. Specifically, these SNPs were associated with MARB in the current study. Previous studies have varied in their reporting of favorable alleles located on the $T G$ gene affecting marbling in B. indicus and B. taurus cattle (Barendse, 1999; Casas et al., 2005; Van Eenennaam et al., 2007). The main factor contributing to this inconsistency is the evaluation of SNPs in B. taurus populations in previous studies. Casas et al. (2005) reported that $\mathrm{SNP}$ effects reported in $B$. taurus species may require the development markers more appropriate for use in $B$. indicus populations. Although no SNPs in the current study were associated with REA, a single SNP located in the $T G$ gene was previously reported to be significantly associated with this trait (Casas et al., 2005).

A single SNP located in the CAST gene was found to be significantly associated with carcass quality (MARB), but no SNPs located within this gene have been significantly associated 
with carcass composition traits (HCW, REA, YG, QG, and WBS). Although previous studies have reported that an SNP located on the CAST gene is associated with tenderness in beef cattle (Schenkel et al., 2006; Smith et al., 2009; Café et al., 2010) no studies have reported SNPs located in this gene to be associated with MARB. Smith et al. (2009) reported an association between a CAST SNP and tenderness in Brahman cattle, and Schenkel et al. (2006) reported that a higher frequency of the favorable CAST allele "A" resulted in a lower percentage of tough steaks, higher fat content, and a difference in REA. The study conducted by Café et al. (2010), which identified SNPs in the CAST gene associated with meat tenderness, reported lower shear force scores in steaks from Brahman cattle that inherited the favorable allele.

A single SNP was significantly associated $(\mathrm{P}<0.001)$ with the carcass quality trait MARB. Previous study by Café et al. (2010) reported that an increase in the frequency of the favorable "G" allele increases meat tenderness. Furthermore, Barendse et al. (2008) reported that the CAPN3 gene was associated with meat tenderness in B. indicus breeds. However, no previous studies have reported significant associations between SNPs on the CAPN3 gene and MARB, as reported in the current study.

Although no SNPs located in the GH1, IGF1, and $A D I P O Q$ genes were identified in the present study as being associated with carcass quality or composition traits, previous reports have found these genes useful when evaluating SNP associations. Previous studies have identified SNPs located in these genes that are significantly associated with growth, carcass quality, and composition traits (Machado et al., 2003; Pereira et al., 2005; Chang et al., 2009). Specifically, Chang et al. (2009) reported a significant association between the IGF1 gene and carcass weight and Pereira et al. (2005) and Mullen et al. (2010) found the GH1 gene to be a favorable candidate gene for cattle growth and carcass traits. Furthermore, multiple studies have indicated that SNPs located in the $A D I P O Q$ gene are associated with REA, MARB, and backfat thickness (Morsci et al., 2006; Shin and Chung, 2013). However, the current study failed to validate previous findings as no SNPs in these three candidate genes were found to be significantly associated with any of the traits evaluated.

Multiple SNPs located in three candidate genes were identified as being significantly associated with carcass quality traits in B. indicus and B. indicus-influenced cattle. However, many of the significant SNPs identified in the current study were located in genes for which no SNPs associated with MARB and QG had previously been characterized in beef cattle. Furthermore, the SNPs identified as significant in the current study were novel, in that they were identified in a purebred $B$. indicus and a $B$. indicus-influenced research population. Thus, because of the unique nature of the population and the small size of the research population, further validation of the SNPs identified here is warranted. Evaluations of these SNPs should be conducted in larger, more diverse populations, in multiple environments and production schemes to further validate the associations of these SNPs with carcass quality and composition traits.

\section{Conflicts of interest}

The authors declare no conflict of interest.

\section{ACKNOWLEDGMENTS}

The current study was approved and funded by the Louisiana Agricultural Experiment Station through the use of State and Federal Hatch funds. 
A.M. Royer et al.

\section{REFERENCES}

Barendse W (1999). Assessing lipid metabolism. Int. Pat. Appl. PCT/ AU98/00882, Int. Pat. Publ. WO 99/23248.

Barendse W, Harrison BE, Bunch RJ and Thomas MB (2008). Variation at the Calpain 3 gene is associated with meat tenderness in zebu and composite breeds of cattle. BMC Genet. 9: 41.http://dx.doi.org/10.1186/1471-2156-9-41

Bauman DE (1992). Bovine somatotropin: review of an emerging animal technology. J. Dairy Sci. 75: 3432-3451. http:// dx.doi.org/10.3168/jds.S0022-0302(92)78119-3

Café LM, McIntyre BL, Robinson DL, Geesink GH, et al. (2010). Production and processing studies on calpain-system gene markers for tenderness in Brahman cattle: 1. Growth, efficiency, temperament, and carcass characteristics. $J$. Anim. Sci. 88: 3047-3058. http://dx.doi.org/10.2527/jas.2009-2678

Casas E, White SN, Riley DG, Smith TPL, et al. (2005). Assessment of single nucleotide polymorphisms in genes residing on chromosomes 14 and 29 for association with carcass composition traits in Bos indicus cattle. J. Anim. Sci. 83: 13-19.

Chang LY, Pitchford WS and Bottema CDK (2009). IGF1 genotypes affect growth not tenderness in cattle. Proc. Assoc. Advmt. Anim. Breed. Genet 18: 512-515.

Davis GP and DeNise SK (1998). The impact of genetic markers on selection. J. Anim. Sci. 76: 2331-2339.

Koohmaraie M, Kent MP, Shackelford SD, Veiseth E, et al. (2002). Meat tenderness and muscle growth: is there any relationship? Meat Sci. 62: 345-352. http://dx.doi.org/10.1016/S0309-1740(02)00127-4

Machado MBB, Alencar MM, Pereira AP, Oliveira HN, et al. (2003). QTL affecting body weight in a candidate region of cattle chromosome 5. Genet. Mol. Biol. 26: 259-265. http://dx.doi.org/10.1590/S1415-47572003000300008

Miller SA, Dykes DD and Polesky HF (1988). A simple salting out procedure for extracting DNA from human nucleated cells. Nucleic Acids Res. 16: 1215.http://dx.doi.org/10.1093/nar/16.3.1215

Morsci NS, Schnabel RD and Taylor JF (2006). Association analysis of adiponectin and somatostatin polymorphisms on BTA1 with growth and carcass traits in Angus cattle. Anim. Genet. 37: 554-562. http://dx.doi.org/10.1111/j.13652052.2006.01528.x

Mullen MP, Berry DP, Howard DJ, Diskin MG, et al. (2010). Associations between novel single nucleotide polymorphisms in the Bos taurus growth hormone gene and performance traits in Holstein-Friesian dairy cattle. J. Dairy Sci. 93: 5959-5969. http://dx.doi.org/10.3168/jds.2010-3385

Pereira AP, Alencar MM, Oliveira HN and Regitano LC (2005). Association of GH and IGF1 polymorphisms with growth traits in a synthetic beef cattle breed. Genet. Mol. Biol. 28: 230-236. http://dx.doi.org/10.1590/S1415$\underline{47572005000200009}$

Schenkel FS, Miller SP, Jiang Z, Mandell IB, et al. (2006). Association of a single nucleotide polymorphism in the calpastatin gene with carcass and meat quality traits of beef cattle. J. Anim. Sci. 84: 291-299.

Shin S and Chung E (2013). Novel SNPs in the bovine ADIPOQ and PPARGC1A genes are associated with carcass traits in Hanwoo (Korean cattle). Mol. Biol. Rep. 40: 4651-4660. http://dx.doi.org/10.1007/s11033-013-2560-0

Smith T, Thomas MG, Bidner TD, Paschal JC, et al. (2009). Single nucleotide polymorphisms in Brahman steers and their association with carcass and tenderness traits. Genet. Mol. Res. 8: 39-46. http://dx.doi.org/10.4238/vol8-1gmr537

Van Eenennaam AL, Li J, Thallman RM, Quaas RL, et al. (2007). Validation of commercial DNA tests for quantitative beef quality traits. J. Anim. Sci. 85: 891-900. http://dx.doi.org/10.2527/jas.2006-512

Wheeler TL, Cundiff LV, Shackelford SD and Koohmaraie M (2001). Characterization of biological types of cattle (Cycle V): carcass traits and longissimus palatability. J. Anim. Sci. 79: 1209-1222. 